\title{
Spondyloarthropathy and osteoarthrosis in three Indomalayan bears: Ursus ursinus Cuvier, 1823, Ursus thibetanus Raffles, 1821, and Ursus malayanus Shaw \& Nodder, 1791 (Mammalia: Carnivora: Ursidae)
}

\author{
Erwin J.O. Kompanje ${ }^{1}$, Peter S.J. Klaver ${ }^{2}$ \& Gilbert Th. de Vries ${ }^{3}$ \\ ${ }^{1}$ Museum of Natural History Rotterdam, P.O. Box 23452, 3001 KL Rotterdam, The Netherlands; ${ }^{2}$ Natura \\ Artis Magistra (Amsterdam Zoo), P.O. Box 20164, 1000 HD Amsterdam, The Netherlands; ${ }^{3}$ Linze 38, 5667 \\ AH Geldrop, The Netherlands
}

Keywords: Ursus ursinus, Ursus thibetanus, Ursus malayanus, spondarthritis, spondyloarthropathy, Reiter's syndrome, vertebral pathology, osteoarthrosis

\begin{abstract}
In the skeletons of three species of Indomalayan bears, pathological changes are described that could be diagnosed as spondyloarthropathy and as discarthrosis/osteoarthrosis.
\end{abstract}

\section{Introduction}

Only two articles could be traced in literature dealing with spondyloarthropathy in Ursidae (Rothschild et al., 1993; Rothschild, 1997). Spondyloarthropathy is a group of nonpurulent arthritides with pauci-articular peripheral and axial joint involvement. The bony outgrowths found on the vertebrae in cases of spondyloarthropathy are called syndesmophytes. These are slim, horizontally disposed bony outgrowths replacing the outer parts of the intervertebral disc and the shorter and longer perivertebral ligaments, thus leading to an intervertebral bridge by means of complex processes involving ossification. The form, symmetry and position of the syndesmophytes are characteristic for the different forms of spondyloarthropathy.

This contrasts with the vertical and chunky osteophytes seen in discarthrosis, which is the result of degeneration of the intervertebral disc with subsequent bone changes. Spondyloarthropathy and discarthrosis (also called osteoarthrosis) are well known in man and several other mammal species. Variants of spondyloarthropathy that are to be con- sidered in the differential diagnosis in Ursidae are conditions similar to Reiter's syndrome or reactive arthritis and psoriatic arthritis, as known in humans.

Osteoarthrosis, as a sign of degeneration, is a well-known condition in older mammals. In the present article some pathological changes in the skeletons of three species of Indomalayan bears are described that could be diagnosed as spondyloarthropathy and as discarthrosis/osteoarthrosis.

\section{Case reports}

Case 1. Ursus ursinus Cuvier, 1823

A female Sloth bear Ursus ursinus, named "Frederica', died in her sleep on 12 October 1995 at the Amsterdam zoo. She had arrived on 29 May 1965 , at the age of six months, from the zoo of Calcutta, India, together with two other females and one male. Having reached almost 31 years of age, she was considered rather old for a Sloth bear: Jones (1982) gave a maximum life span of 28 years and Prater (1971) 40 years. She was the last of the four Sloth bears imported in 1965 . The other three bears died of malignant tumors of the biliary system, which is a common cause of death for old zoo bears, especially Sloth bears (see e.g. Kingston \& Wright, 1985; Canfield et al., 1990; Hellmann et al., 1991; Van der Hage \& Dorrestein, 1994). Frederica gave birth to several pups between 1970 


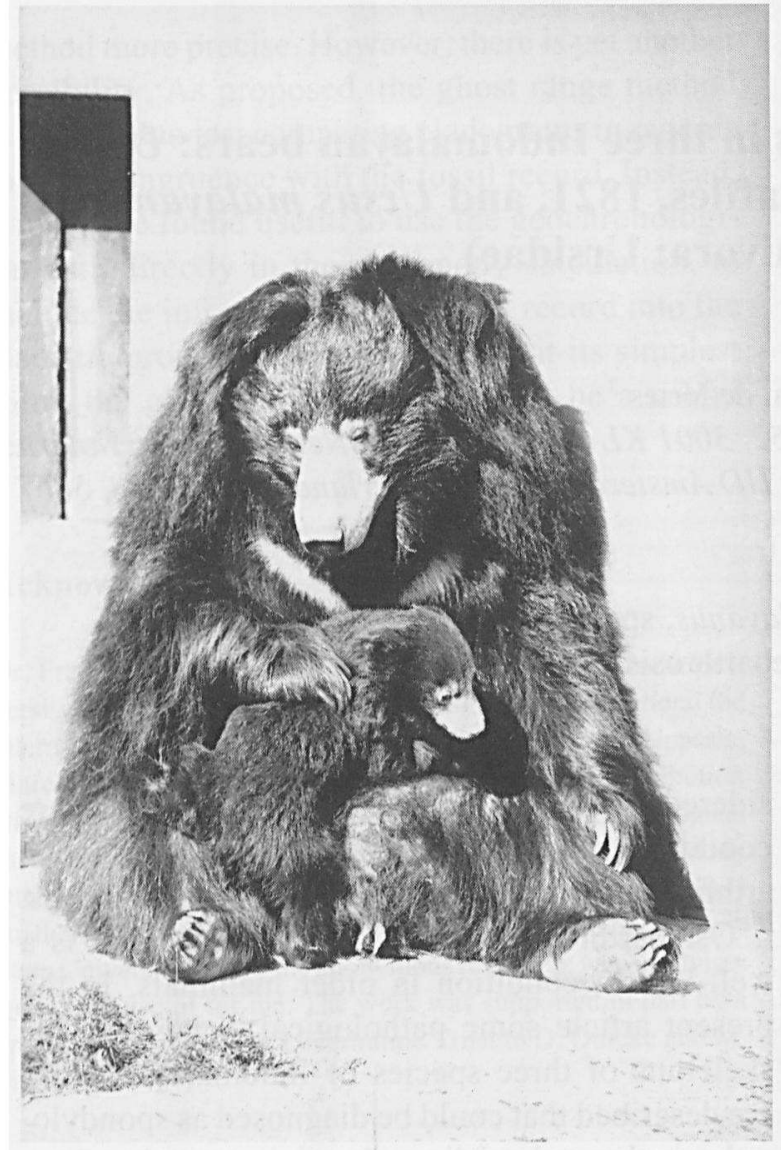

Fig. I. Sloth bear Ursus ursinus 'Sonja' (daughter of 'Frederica'), with pup born December 1987 in the Amsterdam Zoo 'Artis'. Photo: Nationaal Foto-Persbureau B.V., Amsterdam).

and 1987 (registration cards Natura Artis Magistra; Fig. 1).

Autopsy was performed one day after death at the Veterinary Faculty of the University of Utrecht, The Netherlands. The abdominal cavity contained circa 25 litres of yellowish fluid. A mesothelioma was found. Ascites often complicated intra-abdominal malignancies (Kuntze, 1995). The colon showed a thickened red-coloured mucosa; from the contents, Proteus mirabilis, Proteus morganii, Escherichia coli, Streptococcus sp., and Enterobacteriaceae were cultured. A chronic colitis was suspected. Two specimens of the parasite Toxascaris transfuga were found in the stomach; which also contained an amount of blood. The cardia was thickened. Infection with Toxascaris transfuga is common in all species of Ursidae, but is rare in the Sloth bear (Kuntze, 1995).

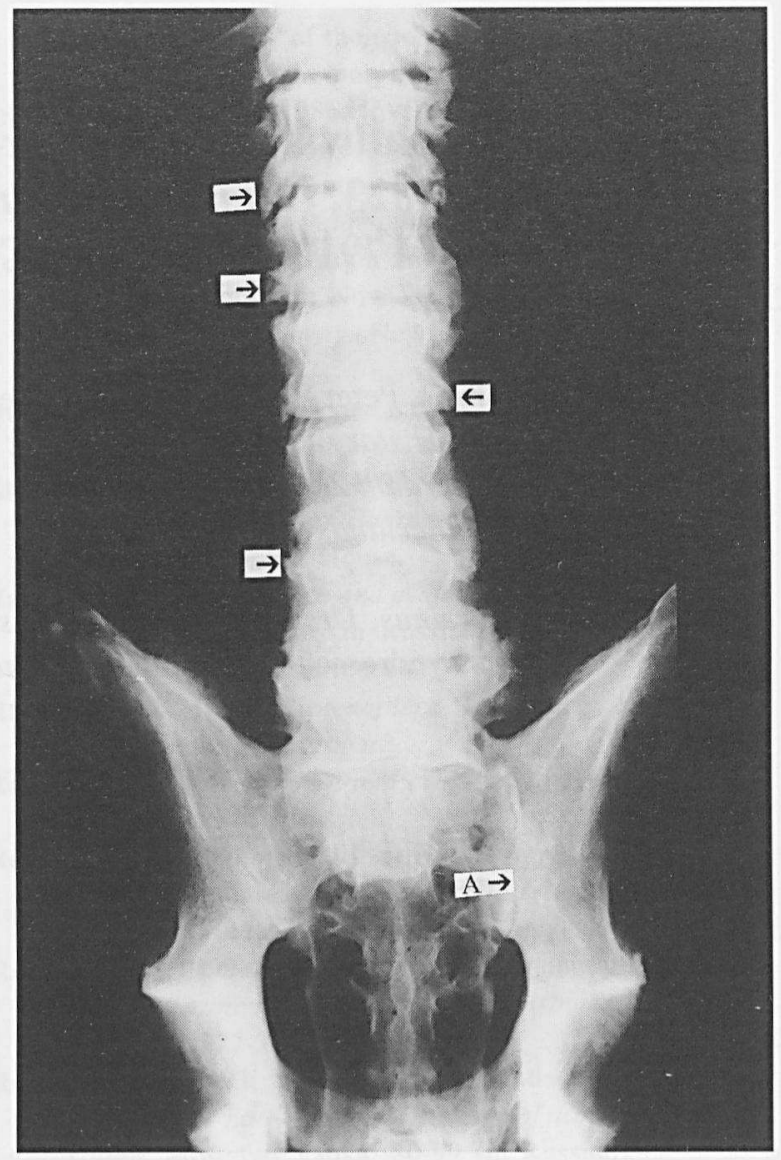

Fig. 2. Postmortem radiograph of the lower thoracic and lumbar vertebrae and pelvis of Ursus ursinus (case 1). Arrowheads indicate syndesmophytes; $\mathrm{A}=$ sacroiliac fusion. Spondyloarthropathy.

The mounted skin and skeleton were saved for the collection of the Natural History Museum of Rotterdam (Natuurmuseum Rotterdam), The Netherlands (reg. no. 999000153). During preparation of the skeleton, severe pathological changes were found on the ventral and anterolateral sides of the lower thoracic and lumbar/sacral region of the vertebral column. The vertebral column was subsequently submitted to radiographic examination. After radiographs were made, the vertebral column was further dissected and the condition of the vertebral ligaments and the intervertebral disci were studied. The bones were then macerated in water, after which examination of the cleaned bones was possible. A preliminary report on this case was published by Kompanje \& Klaver (1998). 


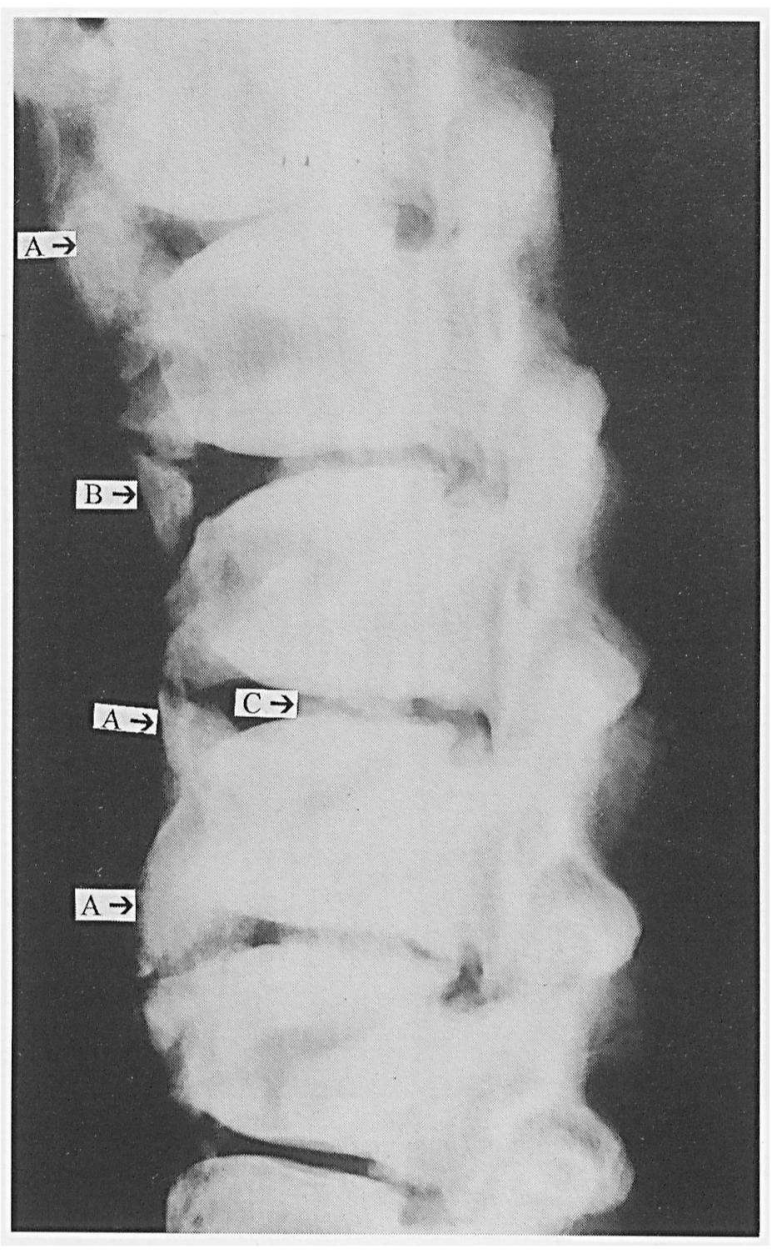

Fig. 3. Postmortem radiograph of the lumbar vertebrae of Ursus ursinus (case 1). $\mathrm{A}=$ nonmarginal syndesmophytes; $\mathrm{B}=$ paradiscal ossicle; $\mathrm{C}=$ calcification of the intervertebral disc. Spondyloarthropathy.

\section{Radiographic examination of the vertebrae}

Radiographs were made of the entire vertebral column including the pelvis in ventrodorsal view. Radiographs in lateral view were made from the lumbar vertebrae. The cervical part showed some abnormalities. On the right anterolateral side of C2 new bone formation was visible as on the zygapophyseal joint between $\mathrm{C} 5$ and $\mathrm{C} 6$. The intervertebral disc space between $\mathrm{C} 6$ and $\mathrm{C} 7$ was narrowed. The radiograph of the lower thoracic and lumbar part showed typical nonmarginal syndesmophytes and paradiscal ossicles. On the radiograph in lateral view, large nonmarginal syndesmophytès were visible in the lower thoracic and upper lumbar region. The syndesmophytes along the lateral part

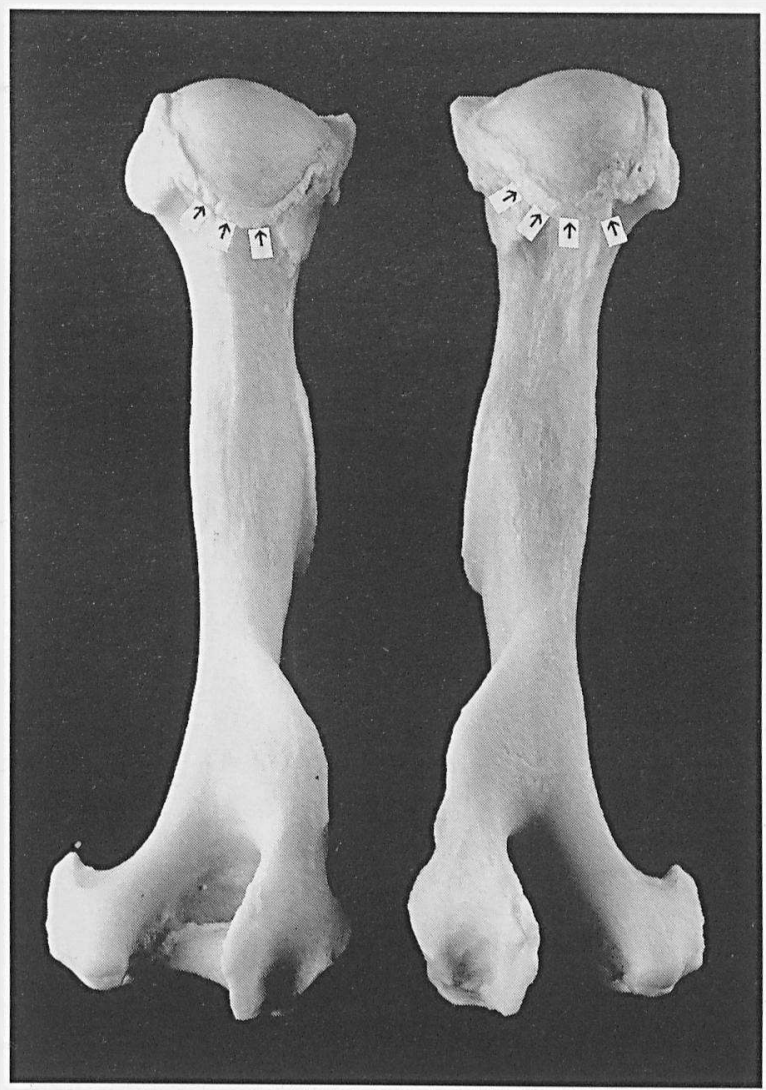

Fig. 4. Humeri of Ursus ursinus (case 1) showing signs of osteoarthrosis (arrowheads).

of the vertebrae, also visible on the radiograph in ventrodorsal view, were vertically disposed and had a 'bullhorn shape' (Fig. 2). Sacroiliac fusion was evident in the upper region (Fig. 2). Calcification of the intervertebral disc was visible in the affected parts of the lumbar vertebrae on the radiograph in lateral view (Fig. 3). The costo-vertebral joints appeared to be normal.

\section{Examination of the macerated skeleton}

Skull. - The skull and dentition were as one should expect from an old zoo bear. Many teeth were lost during the bear's lifetime and those remaining were severely worn. The canines showed signs of dental treatment. Surprisingly, all the apices of the canines were normal. No alveodental abscesses were found.

Forelimbs. - Both humeri and ulnae showed signs of osteoarthrosis (marginal osteophytes on the caput 


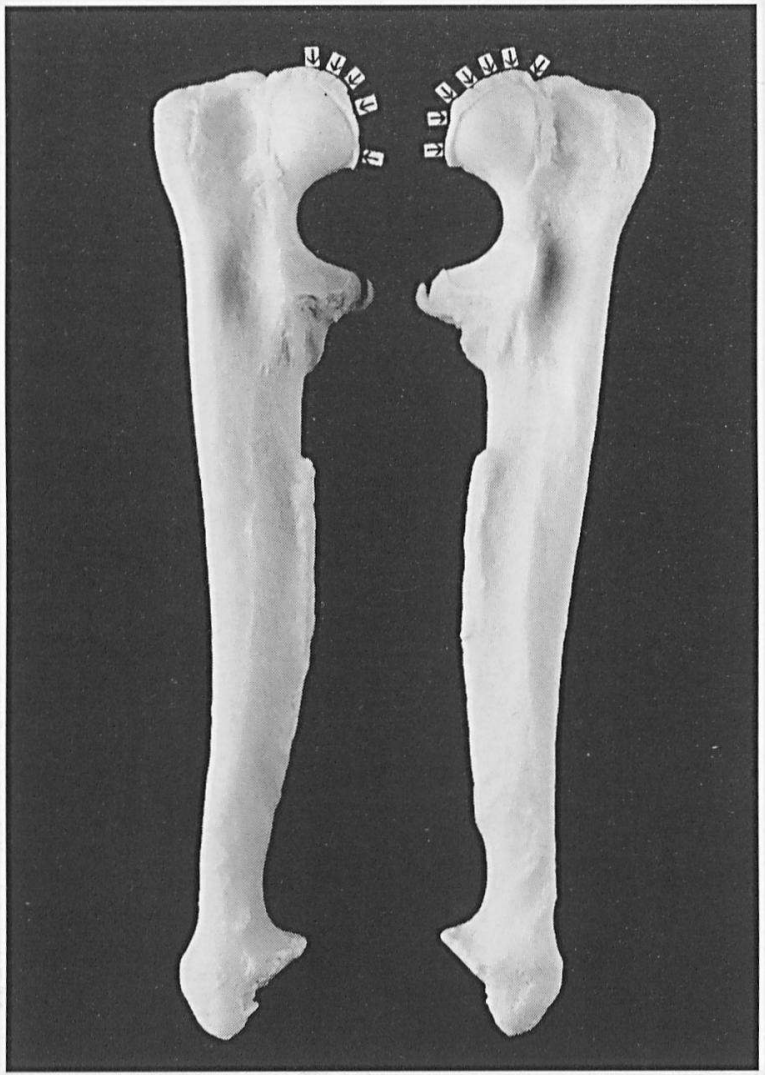

Fig. 5. Ulnae of Ursus ursinus (case 1) showing signs of osteoarthrosis (arrowheads).

humeri and elbow joint) (Figs. $4 \& 5$ ). Some erosive lesions were found on the distal joint surfaces of both radii. Both scapulae showed features of osteoarthrosis on the margins of the glenoid fossa.

The middle three metacarpal bones of the right manus showed signs of healed fractures. The other two metacarpal bones, the carpal bones and phalanxes were normal, as were the bones of the left manus.

Hindlimbs. - Impressive features of osteoarthrosis were found on both caput femoris (eburnation, erosion, marginal osteophytes) (Fig. 6). The knee joint showed only mild features of osteoarthrosis. The right ankle joint showed a mixture of osteoarthrosis and erosive arthritis (the latter is a feature of spondyloarthropathy). The left one is only affected by osteoarthrosis. Large enthesophytes (calcifications of tendon attachments) were found on the dorsal side of the upper end of both tibiae (Fig. 7).

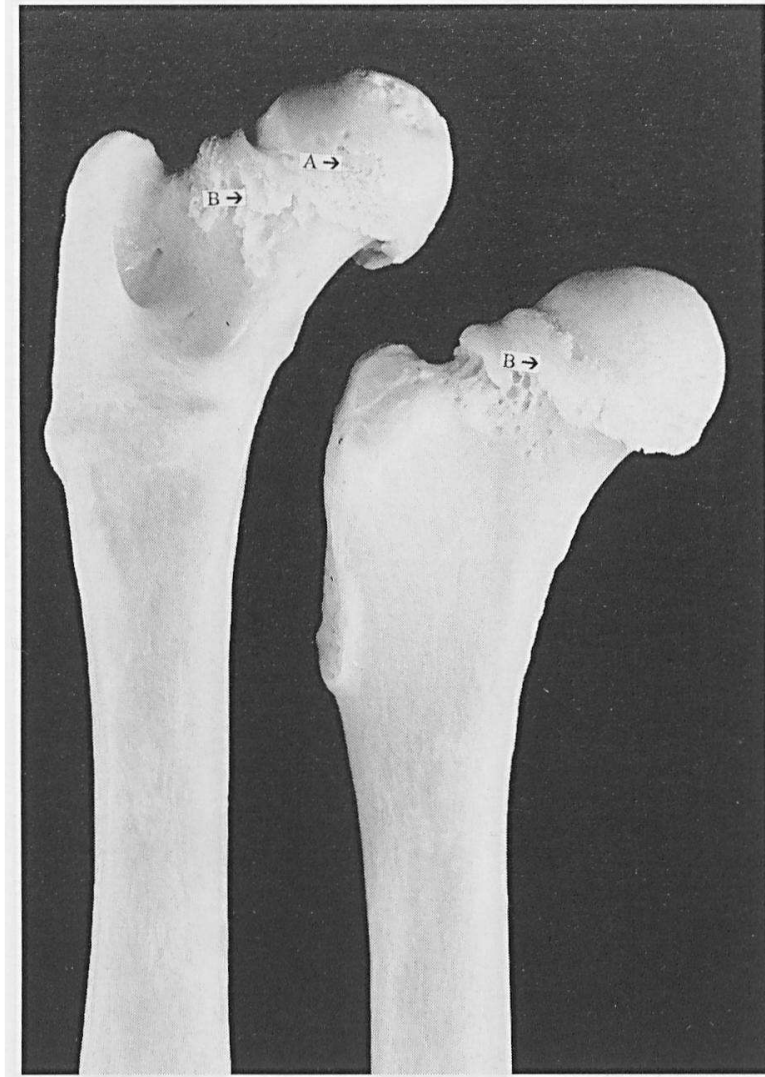

Fig. 6. Capita femoris of Ursus ursinus (case 1) showing features of osteoarthrosis. $\mathrm{A}=$ erosion of the cortex; $\mathrm{B}=$ marginal osteophytes.

Severe erosive arthritis was found in the right subtalar and ankle joint. Erosions were also found between the third and fourth metatarsalia of the left foot. All the other bones of the feet were normal.

Cervical vertebrae. - Arthrosis and erosion was found in all zygapophyseal joints, most severe between $\mathrm{C} 5$ and $\mathrm{C} 6$, already visible on the radiograph. Marginal osteophytes, a sign of discarthrosis, were found on the ventral margins of all vertebrae. A large nonmarginal syndesmophyte was found on the right anterolateral side of $\mathrm{C} 2$. Erosion was found on the caudal vertebral endplate of $\mathrm{C} 3$ and the cranial vertebral endplate of $\mathrm{C} 4$. Severe erosion was found on the caudal endplate of $\mathrm{C} 6$ and cranial endplate of C7 (Fig. 8); normal covering bone plate was completely absent.

Thoracic vertebrae. - Arthrosis was found in all 


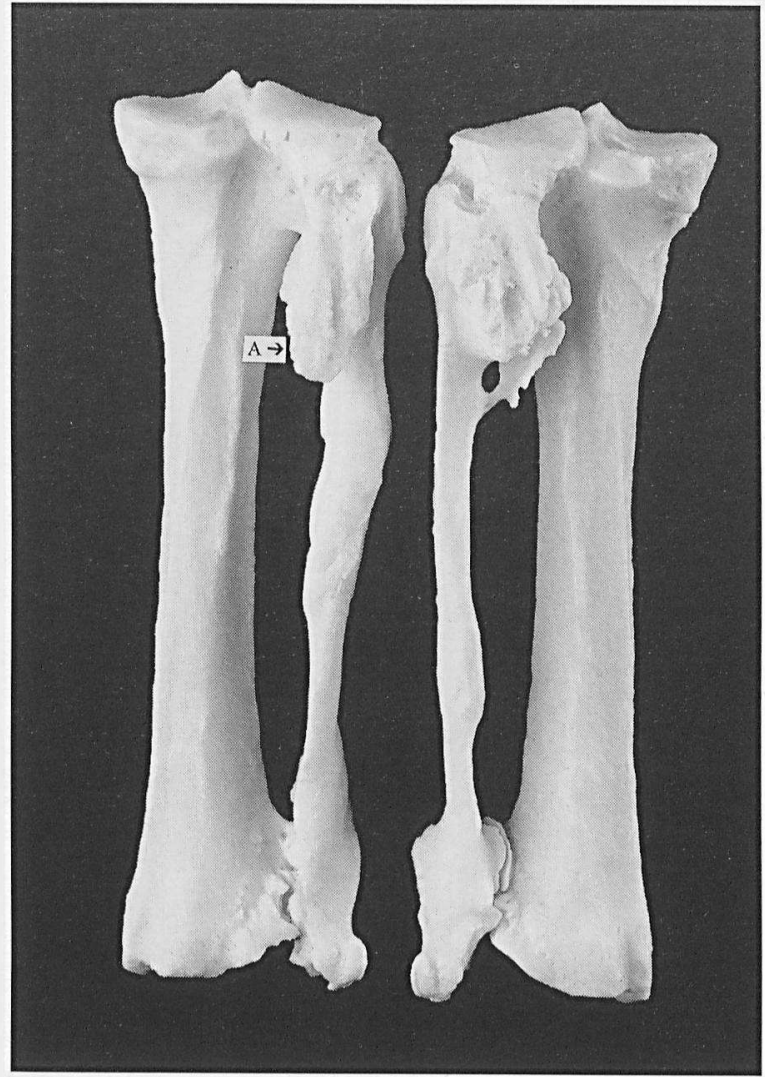

Fig. 7. Tibiae of Ursus ursinus (case 1) with (A) large enthesophytes on the dorsal side of the upper ends.

zygapophyseal joints, but most severe between Th8Th9 and Th9-Th10. The whole area of contact was covered with erosion and perforations of varying size and there was new bone formation and eburnation. On several vertebrae large nonmarginal syndesmophytes were found, the most severe being in the lower thoracic spine after Th9. On some of the vertebrae marginal osteophytes were found, as a sign of discarthrosis. Th3, Th4 and Th5 were completely normal.

Lumbar vertebrae. - Large nonmarginal syndesmophytes were found on the ventral and anterolateral sides of all lumbar vertebrae. Involvement of the zygapophyseal joints was visible (Fig. 9). Paradiscal ossicles were found on the ventral side between L1 and L2, also visible on the radiograph in lateral view (Fig. 3). Extensive erosions were foünd on the caudal endplate of L5. Between L6 and the sacrum, ankylosis was found. Large nonmarginal

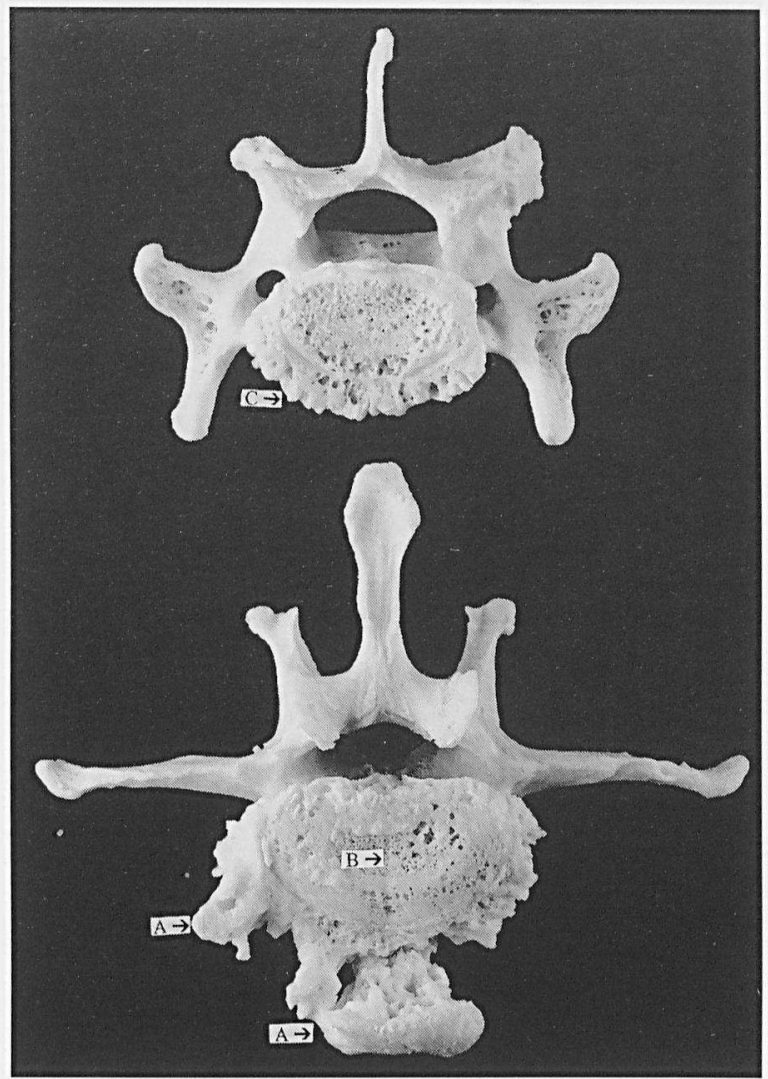

Fig. 8. Seventh cervical (upper) and a lumbar (lower) vertebrae of Ursus ursinus_(case 1) with (A) large nonmarginal syndesmophytes; (B) severe erosion of the vertebral endplate and (C) marginal osteophytes. Discarthrosis and spondyloarthropathy.

syndesmophytes were found in this region (Fig. 8).

Pelvis, sacrum, and caudal vertebrae. - The sacroiliac fusion was asymmetric, on the left side in ventral view more complete than on the right. On the dorsal side the fusion was complete on both sides (Fig. 10). Extensive osteoarthrosis was found in the hip joints.

\section{Comments on case 1}

On the spine, osteophytes and syndesmophytes were found as features of two different conditions: discarthrosis (spondylosis deformans) and spondyloarthropathy. Mixtaosteophytes as a combination of arthritis and arthrosis were also recognized.

Initial alterations in spondyloarthropathy are apparent at the thoracolumbar and lumbosacral 


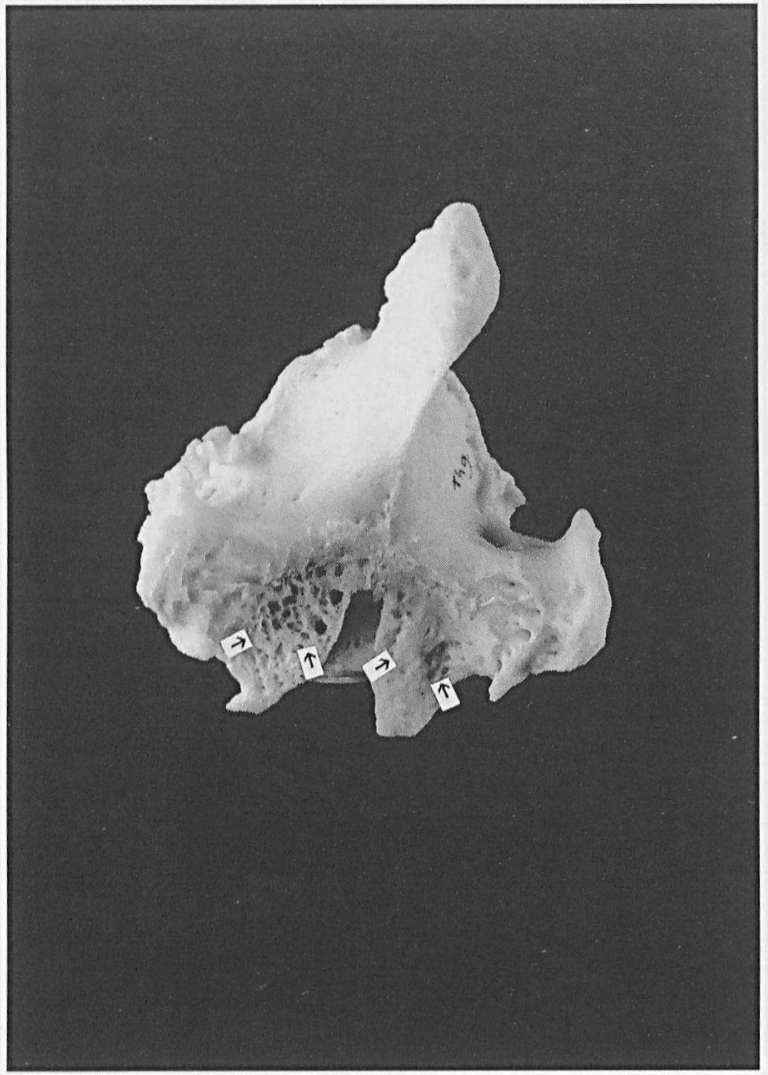

Fig. 9. Severe erosion of the zygapophyseal joints (arrowheads) in a lumbar vertebra of Ursus ursinus (case 1).

junctions, as is seen in this case. Asymmetric fusion of the sacroiliac joints is typical for spondyloarthropathy of Reiter's type and for psoriatic arthritis. The syndesmophytes in this Sloth bear were mostly unilateral and asymmetric in distribution, looking broad and bulky, characteristic of Reiter's syndrome (Kerr \& Resnick, 1985).

\section{Case 2. Ursus thibetanus Raffles, 1821}

The cleaned skeleton of an adult female Asiatic black bear Ursus thibetanus was obtained by the third author. The bear died in 1994 in Zwartberg zoo, Genk, Belgium. Unfortunately, neither professional autopsy, nor radiographic examination was performed, and there was no information available regarding age or life history. Judged from the skeletal development, this animal was advanced in age. The skeleton is kept in the Natural History Museum Rotterdam (reg. no. 999000835).

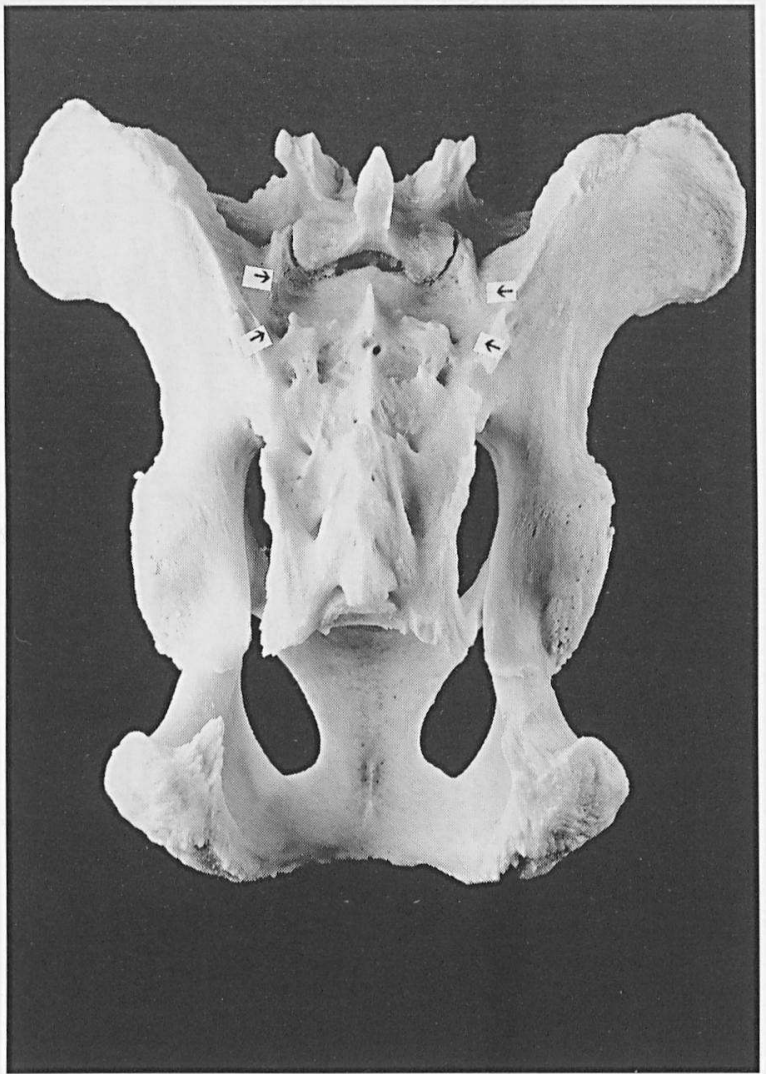

Fig. 10. Pelvis and sacrum of Ursus ursinus (case 1) showing sacroiliac fusion on both sides (arrowheads). Spondyloarthropathy.

\section{Examination of the macerated skeleton}

Skull. - The skull and dentition were almost completely normal. The canines were severely worn, as is normal in a zoo bear. No alveodental abscesses were apparent.

Forelimbs. - The scapulae, humeri, radii and ulnae showed signs of severe osteoarthrosis (Figs. 11 \& 12). In most of the metacarpalia and carpalia and some of the phalanxes, marginal osteophytes were found. No erosive lesions were visible.

Hindlimbs. - On the femora and tibiae impressive signs of osteoarthrosis were found (Fig. 13). Both knee joints showed severe signs of degeneration. On the patellae large marginal spurs were visible. The tarsalia and metatarsalia showed also degenerative features in the form of marginal osteophytes. 


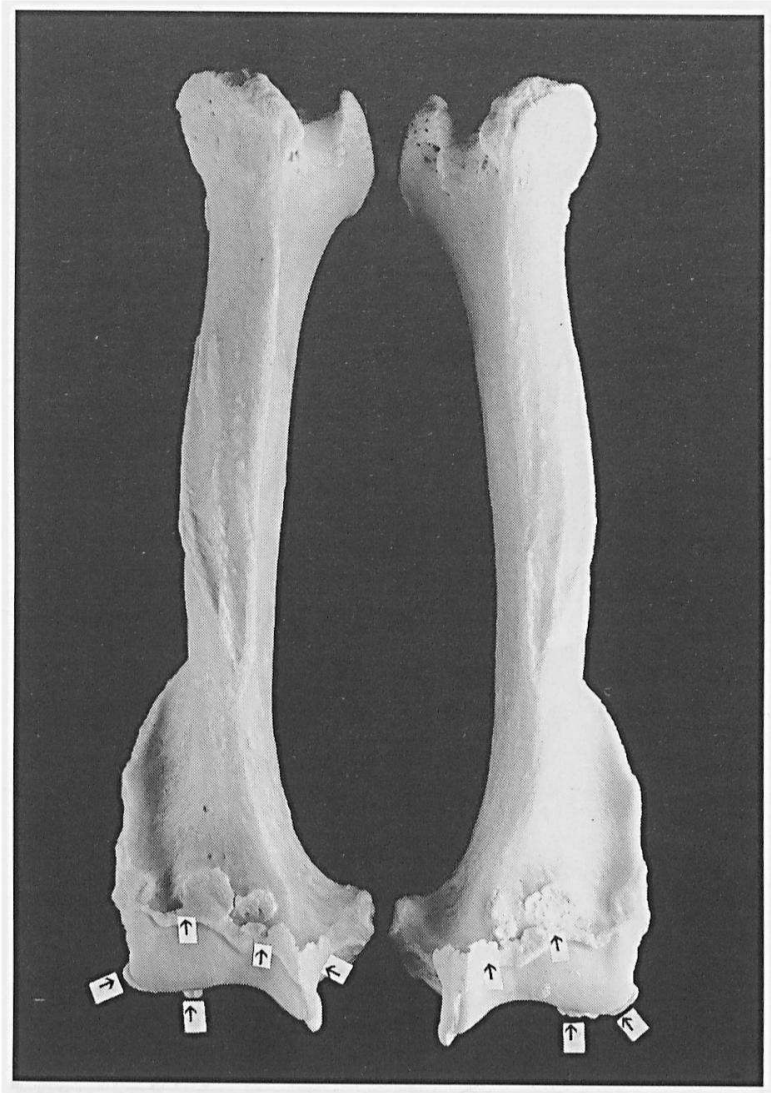

Fig. 11. Humeri of Ursus thibetanus (case 2) with severe osteoarthrosis (arrowheads showing marginal osteophytes).

Cervical vertebrae. - Large nonmarginal syndesmophytes were found on the left ventral side of $\mathrm{C} 5$ and C6. Erosion of the vertebral endplate was found on the caudal endplate of $\mathrm{C} 3$, cranial and caudal endplate of $\mathrm{C} 4, \mathrm{C} 5$ and $\mathrm{C} 6$, and the cranial endplate of C7. Some signs of arthrosis of the zygapophyseal joints were found on all cervical vertebrae. Marginal osteophytes were found on $\mathrm{C} 2$ up to and including C7.

Thoracic vertebrac. - All thoracic vertebrae showed severe pathological changes. On all margins degenerative osteophytes were found. On the right ventral side of Th6 up to and including Th11 large nonmarginal new bone formation was found, possibly nonmarginal syndesmophytes. No ankylosis was observed between any of the thoracic vertebrae. Signs of arthrosis of the zygapophyseal joints were found in most of the thoracic vertebrae. Erosion

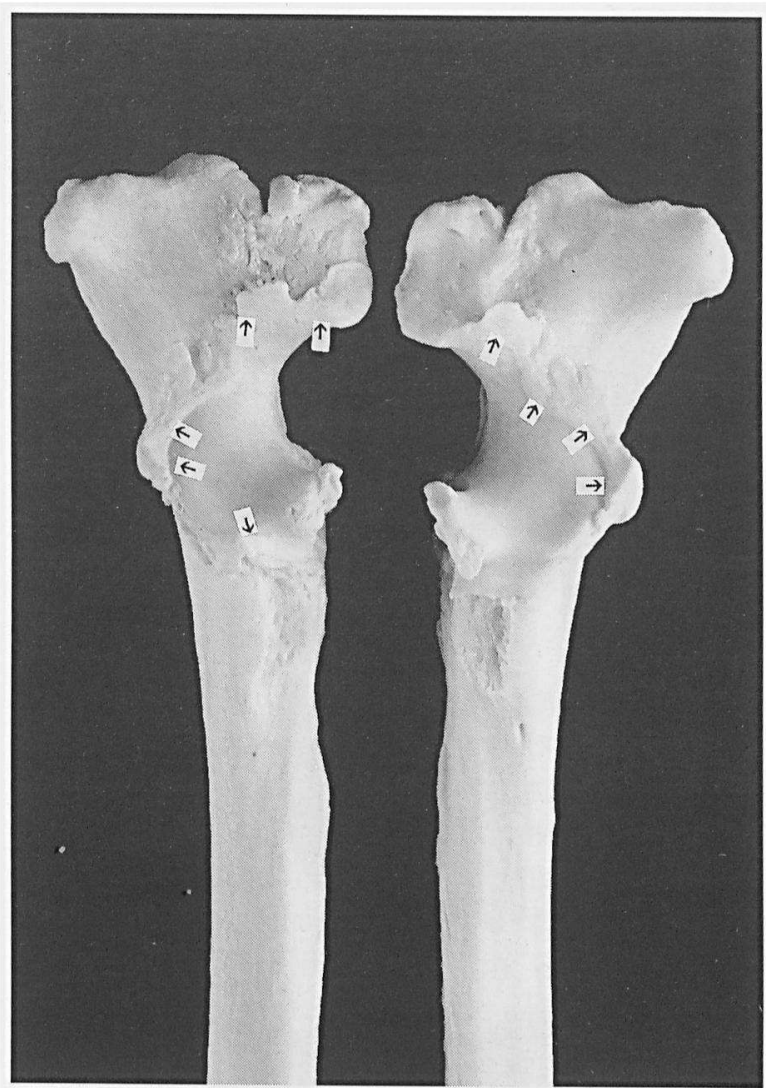

Fig. 12. Proximal ends of the ulnae of Ursus thibetanus (case 2) with severe osteoarthrosis (arrowheads indicating marginal osteophytes).

of the vertebral endplate was mostly confined to the mid-thoracic vertebrae. On the 13th thoracic vertebrae, large nonmarginal syndesmophytes were found lipping with those on the 14th thoracic vertebra. This 14th thoracic vertebra was found completely fused with the first lumbar vertebra (Fig. 14).

Lumbar, sacral vertebrae and pelvis. - There was a complete fusion between the 14th thoracic and all lumbar vertebrae (Fig. 14). The new bone formation has fused the vertebrae on all sides. There was complete fusion in all zygapophyseal joints. The sacroiliac fusion was complete and symmetric. Between the 5th lumbar vertebra and the sacrum, impressive new bone formation (syndesmophytes) was found, without fusion of these syndesmophytes or of the zygapophyseal joints. 


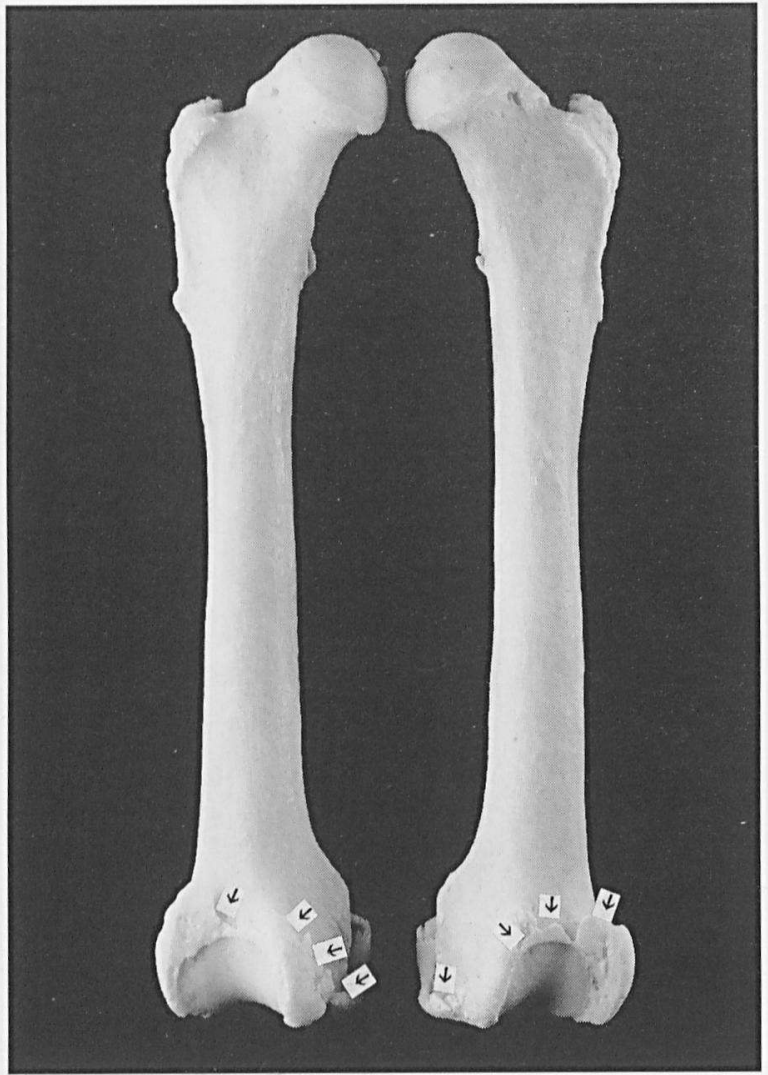

Fig. 13. Femora of Ursus thibetanus (case 2) showing marginal osteophytes (arrowheads).

\section{Comments on case 2}

On the spine, osteophytes and syndesmophytes were found as features of degeneration (discarthrosis, spondylosis deformans) and spondyolarthropathy. Mixtaosteophytes were also found. Initial alternations of spondyloarthropathy are most usually found in the thoracolumbar and lumbosacral junctions, as in the case described here. The fusion of the sacroiliac joints was complete. Most likely this case represents a combination of osteoarthrosis/discarthrosis and spondyloarthropathy of Reiter's type or psoriatic arthritis.

\section{Case 3. Ursus malayanus Shaw \& Nodder, 1791}

The cleaned skeleton of an adult female Sun bear Ursus malayanus was also obtained by the third author. This bear came from the same zoo as the one treated in the former case. Once again, profes-

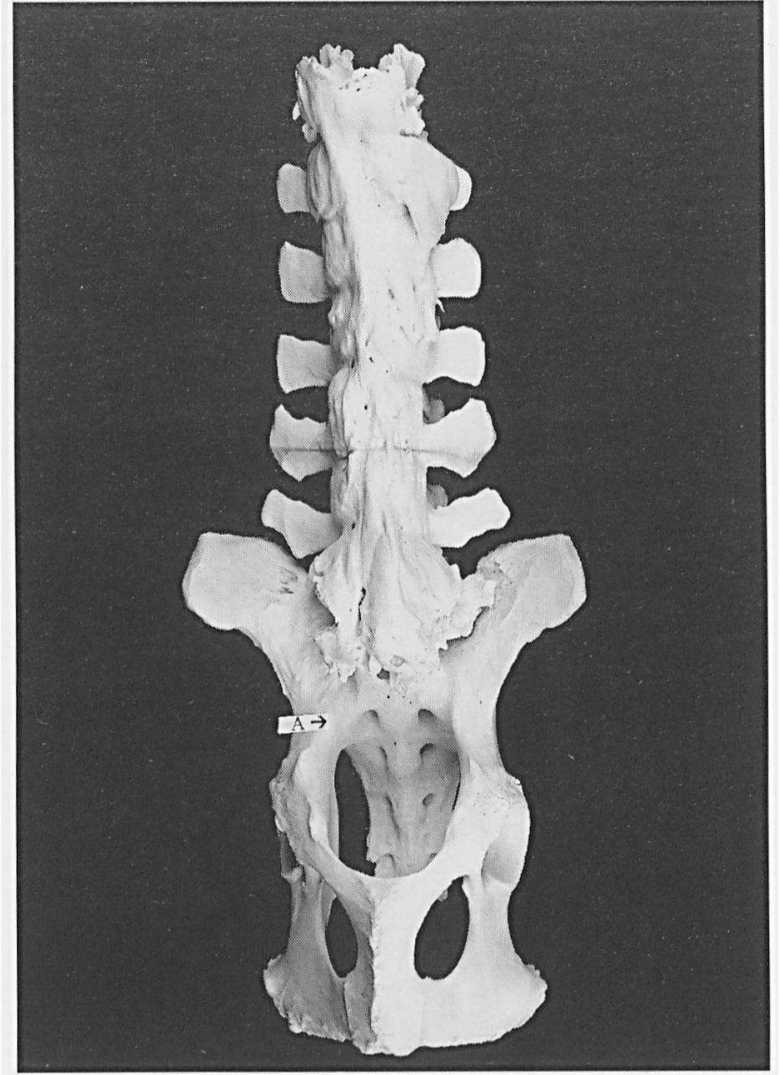

Fig. 14. Lower thoracic and lumbar vertebrae and pelvis/sacrum of Ursus thibetanus (case 2). Complete fusion of the vertebrae and (A) complete sacroiliac fusion. Spondyloarthropathy.

sional autopsy and/or radiographic examination were not performed and subsequently no information regarding age and/or life history was available. The skeleton is kept in the private collection of the third author.

\section{Examination of the macerated skeleton}

Skull. - The skull and dentition were as one should expect from a bear held in captivity. Signs of large alveodental abscesses were found around all apices of both upper canines, the left lower canine, and the lower incisives.

Forelimbs. - Both humeri showed some small marginal osteophytes on the margins of the caput humeri (osteoarthrosis). Scapulae were normal. Some erosion of unknown etiology was found on the proximal joint surfaces of the right ulna. The left ulna and the radii were normal. All right carpalia, 
metacarpalia and phalanxes were normal. All left carpalia and metacarpalia were likewise normal. Some of the left phalanxes showed irregularly new bone formation and destruction of bone, as the result of osteomyelitis. $x_{1} i \ldots$

Hindlimbs. - Femora, tibiae, and fibulae were normal. The left fibula and tibia were fused in the proximal joint, most probably due to calcification of tendon attachments. All the bones of the feet were normal.

Cervical vertebrae. - All cervical vertebrae were completely normal.

Thoracic vertebrae. - The first seven thoracic vertebrae were normal. The 8th up to and including the 15 th thoracic vertebrae showed large marginal and nonmarginal syndesmophytes. The syndesmophytes impinged with each other, but no ankylosis was found. All vertebral endplates and zygapophyseal joint surfaces were normal.

Lumbar vertebrae. - All lumbar vertebrae showed small and some large marginal and nonmarginal syndesmophytes. All vertebral endplates and zygapophyseal joint surfaces were normal.

Pelvis, sacrum, and caudal vertebrae. - The sacroiliac fusion was smooth and symmetric. Some syndesmophytes were found on the right upper margin of S1. The first caudal vertebra was fused with the last sacral one. Both hip joints were normal.

\section{Discussion}

Discarthrosis is defined as the structural and functional failure of the discal joint, combining degeneration of the intervertebral disc and accompanied or followed by bone changes. The condition starts as degeneration of the disc, followed by vertically disposed marginal osteophytes, disrupture of the vertebral endplate, and changes in the subchondral bone in the form of sclerosis, erosions, and eburnation. Osteoarthrosis of the zygapophyseal joints is called zygarthrosis (François et al., 1995̈).
Features of discarthrosis were found in all three bear skeletons examined. However, ankylosis of two or more vertebrae is uncommon in discarthrosis.

Reiter's syndrome and psoriatic arthritis are members of the spondyloarthropathy (synonyms: spondyloarthritis, spondarthritis) network. The cause of spondyloarthropathy is probably the combination of genetic and environmental factors (e.g. infections elsewhere). Reiter's syndrome has often an infectious "trigger" (e.g. Chlamydia, Shigella, Yersinia, Salmonella, Campylobacter, Mycoplas$m a$ ). There is often asymmetrical peripheral nonpurulent arthritis in more than five joints. Sacroiliac fusion is evident in this condition.

Unquestionably the dominant axial pathology in all three cases described here can be diagnosed as spondyloarthropathy. The (nonmarginal) syndesmophytes (all cases), zygapophyseal joint involvement (case 1 and 2) and fusion (case 2), smoothly formed ankylosis (case 2), and sacroiliac fusion (all cases) are diagnosfic for this condition. Based on these features, other vertebral conditions like advanced discarthrosis and Diffuse Idiopathic Skeletal Hyperostosis (DISH) can be ruled out. In all cases discarthrosis is present in the vertebral column as well.

Discarthrosis has been diagnosed in the Pleistocene Ursus spelaeus (cf. Fischer, 1995; TasnádiKubacska, 1962), but among these fossil cases are most probably those in which the pathological changes are characteristic for spondyloarthropathy (fused zygapophyseal joints, smoothly formed ventrally disposed ankylosis, nonmarginal syndesmophytes). Wallach \& Boever (1983) illustrated a case of arthritis in an old Grizzly bear, Ursus arctos horribilis. Klöppel (1991) described a case of vertebral deformation in a 40 year old Kodiak bear, Ursus arctos middendorfii. He diagnosed the pathology as osteodystrophia deformans (Paget's disease) or as a severe case of infectious spondylitis. Rothschild \& Turnbull (1987) described a case of a treponemal infection in an Indiana Pleistocene bear, Arctodus simus, resulting in an erosive spondylitis of thoracic 'vertebrae.

Osteoarthrosis (synonyms: osteóarthritis, arthrosis deformans, discarthrosis) is found in fossil and contemporary bears. Tasnădi-Kubacska (1935, 
1962) illustrated some good examples of this condition in Ursus spelaeus. This material can, however, include cases of inflammatory erosive arthritis (called by the author "arthritis deformans" and 'arthritis erosiva'. We likewise found classic features of osteoarthrosis, especially in the skeletons of Ursus ursinus and Ursus thibetanus. In other carnivores (e.g. Hyaenidae and Felidae), osteoarthrosis is rare and inflammatory erosive arthritis is more common (Rothschild \& Rothschild, 1994; Rothschild et al., 1998).

Rothschild et al. (1993) found in $86 \%$ of 243 adult bear skeletons (all species) calcification of the annulus fibrosus, forming syndesmophytes, zygapophysial joint fusion and sacroiliac joint fusion as features of spondyloarthropathy. They concluded that it is most plausible to consider Reiter's syndrome as the cause of these deformations. In another article, Rothschild (1997) mentions $25 \%$ occurrence of type B rheumatoid arthritis and spondyloarthropathy in contemporary bears. In Hyaenidae, Rothschild \& Rothschild (1994) found axial involvement in $57 \%$ of the material examined. Spondyloarthropathy was documented in $3.7 \%$ of 386 large Felidae (Rothschild et al., 1998).

It is not completely clear which factor triggered the development of the spondyloarthropathy in the three ursids described. Seen the form and distribution of the nonmarginal syndesmophytes found in the first two cases, Reiter's syndrome or reactive arthritis is most likely in these cases. In man, the classical reactive arthritis is triggered by two major types of bacterial infection: in the first place, sexually transmitted infection (mostly by Chlamydia trachomatis) and in the second place a gastrognteritis due to, e.g., Salmonella ssp., Shigella ssp., Yersinia ssp., or Campylobacter ssp. Infection with parasites of the genus Ascaris can cause reactive arthritis in man (Khan, 1995).

Rothschild et al. (1993) concluded that the sexually transmitted variant was most likely, seen the high frequency of fractured bacula in Ursidae. However, these fractured penis bones are especially known in Ursus spelaeus (Tasnádi-Kubacska, 1933; 1962), and are less common (less described) in recent bears. Unfortunately, Rothschild et al. (1993) gave no percentages of fractured bacula in the 280 bears examined by them. Tasnádi-Kubacska (1933) mentioned only 15 known cases of fractured bacula in Ursus spelaeus. Furthermore, the relationship between fractured penis bones and sexually transmitted diseases is not completely clear to us. In our understanding, a bear can fracture his baculum without transmitting or obtaining bacterial or viral diseases.

The 'bullhorn' shaped nonmarginal syndesmophytes that are visible on the radiographs made of the vertebral column in the examined Ursus ursinus (case 1) are characteristic of Reiter's syndrome (Dihlmann, 1986). On the macerated bones bulky syndesmophytes are found, also more often found in Reiter's syndrome than in other variants of spondyloarthropathy (Kerr \& Resnick, 1985). The sacroiliac involvement is persistent in this case, but appears to be asymmetrical and not complete. This Sloth bear was suffering from a (chronic) colitis, which made the enteropathic variant of Reiter's syndrome plausible.

\section{Acknowledgements}

We thank Drs. Marein van der Hage and Dr. Gerry M. Dorrestein, Veterinary Faculty, University of Utrecht for the postmortem on case 1. The photographs (except Fig. 1) were made by $\mathrm{Mr}$. Rob "t Hart.

\section{References}

Canfield P, Bellamy T, Blyde D, Hartley, WJ, Reddacliff G, Spielman D. 1990. Pancreatic lesions and hepatobiliary neo-

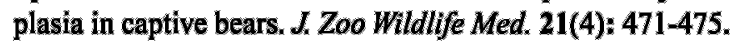

Dihlmann W. 1986. Radiologic atlas of rheumatic diseases. Stuttgart: Georg Thieme Verlag.

Fischer K. 1995. Der Höhlenbär Ursus spelaeus Rosenmüller \& Heinroth, 1794 von Rübeland (Harz). Braunschw. naturkdl. Schr. 4(4): 709-742.

François RJ, Eulderink F, Bywaters EGL. 1995. Commented glossary for rheumatic diseases, based on pathology. Annals Rheum. Dis. 54: 615-625.

Hage M, van der, Dorrestein GM. 1994. Why do bears die in captivity? In: Dorrestein GM, Kahraman MM, eds., Proceedings International Conference on Aspects of Bear Conservation, Bursa, Turkey, 1994: 125-130.

Hellmann J, Hofmeister R, Göltenboth R. 1991. Das auftreten von Tumoren bei Großbären (Ursídae) - eine Líteraturübersicht sowie sechs weitere Fallbeschreibungen. Berl. Münch. tierärztl. Wochenschr. 104: 262-268. 
Jones ML. 1982. Longevity of captive mammals. Zool. Garten 52: 113-128.

Kerr R, Resnick D. 1985. Radiology of the seronegative spondyloarthropathies. Clinics in Rheumat. Dis. 11(1): 113-146.

Khan MA. 1995. Arthritis and autoimmunity. Report on the 15th Sigrid Jusêlius Symposium. Rheumatol. Int. 15: 39-42.

Kingston RS, Wright FH. 1985. Bile duct carcinoma with widespread metastases in a sloth bear. $J$. Zoo Anim. Med. 16: 1620.

KIöppel G. 1991. Bildbericht über eine Wirbelsäuleerkrankung bei 1.0 Kodiakbär (Ursus arctos middendorffi). Berl. Münch. Tierärztl. Wochenschr. 104: 27-29.

Kompanje EJO, Klaver PSJ. 1998. Spondarthritis (spondyloarthropathy) and osteoarthrosis in an old female Sloth bear (Ursus ursinus Cuvier, 1823), A case report. Proceedings European Association of Zoo and Wildlife Veterinarians (EAZWV), Second Scientific Meeting, Chester, May 21-24, 1998: 473-479.

Kuntze A. 1995. Bären. In: Göltenboth R, Klös HG, eds. Krankheiten der Zoo- und Wildiere, Berlin; Blackwell Verlag, 106120.

Prater SH. 1971. The book of Indian animals. Bombay: Bombay Natural Hístory Society.

Rothschild BM. 1997. Two faces of "rheumatoid arthritis" $\times$ type
A versus type B disease, J. Clin. Rheumatol, 3(6): 3-338.

Rothschild BM, Rothschild C. 1994. No laughing matter: spondyloarthropathy and osteoarthritis in Hyaenidae. $J$. Zoo Wildlife Med. 25(2): 259-263.

Kothschild BM, Rothschild C, Woods RJ. 1998. Inflammatory arthritis in large cats: an expanded spectrum of spondyloarthropathy. $J$ Zoo Wildlife Med. 29(3): 279-284.

Rothschild BM, Turnbull W. 1987. Treponemal infection in a Pleistocene bear. Nature 329: 61-62.

Kothschild, BM, Wang X, Cifelli R. 1993. Spondyloarthropathy in Ursidae: a sexually transmitted disease? Nat. Geogr. Res. Explor: 9: 282-284.

Tasnádi-Kubaeska A. 1933. Geheilte Fracturen am Penisknochen des Höhlenbären. Palaeobiologica 5: 159.

Tasnádi-Kubacska A. 1935. Pathologísche Untersuchungen an Ungarländischen Versteinerungen, Annls. Musei nation. Hungarici, Pars mineralogica, geologica, palaeontologica 29: 1-8.

Tasnádi-Kubacska A. 1962. Paläopathologie, Jena: Gustav Fischer Verlag.

Wallach JD, Boever WJ. 1983. Diseases of exotic animals. Medical and surgical management. Philadelphia: W.B. Saunders.

Accepted: 19 July 2000 